\title{
A review of the impact of parking policy measures on travel demand
}

Bernard P. Feeney, National Institute for Physical Planning and Construction Research, Dublin, Ireland Reprint from Transportation Planning and Technology, 1989, Vol 13, pp 229 - 244 


\title{
A REVIEW OF THE IMPACT OF PARKING POLICY MEASURES ON TRAVEL DEMAND
}

\author{
BERNARD P. FEENEY \\ National Institute for Physical Planning and Construction Research, Dublin, Ireland
}

(Received August 16, 1988)

\begin{abstract}
This paper reviews the empirical evidence relating to the impact of parking policy measures on the demand for parking and for travel. Disaggregate modal choice models, disaggregate parking location models and site-specific studies of parking behaviour are examined. With regard to modal choice models, it is concluded that few studies deal adequately with parking factors, but that there is some support for the view that parking policy measures are a relatively important influence on modal choice. When parking location models are examined parking policy variables are shown to have a substantial impact on choice of parking location. With regard to site-specific studies, the paper concludes that there is a great variation in the parking price elasticities quoted, which reflects partly the methodological problems associated with such studies. Suggestions to improve model specification are made.
\end{abstract}

KEY WORDS: Parking, travel demand, parking policy measures.

\section{INTRODUCTION}

The purpose of this paper is to review the impact of urban parking policy measures on the demand for parking, and, by implication, on travel, in general.

Assessing the contribution of parking measures to urban policy objectives is a two-step process. There is a need to consider both the effect on traffic levels and patterns and the subsequent impact of these on broad policy objectives. For example, the contribution of a given set of parking measures to the goal of energy conservation, depends on the degree to which travel demand reacts to such measures, and the implications of the altered travel situation for energy consumption. This paper is concerned solely with the first step in this process. The emphasis is largely but not exclusively on the effect of parking policy measures on commuting travel. The concern of the paper is to review the quantitative rather than qualitative effects of parking, and where possible to summarise these effects as demand elasticities.

Parking policy measures operate in two ways: firstly, by changing the level or structure of parking charges facing the motorist; and secondly, by changing the supply of parking spaces. The latter should be interpreted as referring not only to the physical supply of parking, but also to the restriction of access to parking, at certain times of the day, for certain durations or to certain classes of user. The motorist can respond to these measures by:

-a change in parking location

-a change in the starting time for the trip

-a change in the mode used

-a change in trip destination

-abandonment of the trip 
In examining empirical sources of the travel response to parking policy variables, it is important to establish which or how many of the travel responses identified above are under analysis. This is particularly relevant, when an attempt is made to summarise the demand response in the form of elasticities. For example, empirical results relating to the parking price elasticity of demand for car use need have no similarity to these for use of particular parking locations. In reviewing and comparing the data available from various empirical sources, it is important to bear this in mind.

The extent to which any of these responses occurs is determined, in part, by the trip purpose. For the journey to work-which is the main concern here-there is little or no prospect, in the short term, of either changing the trip destination or of abandoning the trip. The more likely responses are therefore a change in parking location, a rescheduling of the trip or a change in the mode used. With regard to journey rescheduling, the impact of parking policy measures is probably limited. Such measures are usually applied when there is pressure on parking spaces. In such a situation, although the individual response to parking supply constraints may be to start the journey to work earlier, this implies displacement of existing parkers. In any event, journey scheduling has received little attention in the literature and the available evidence does not consider the role of parking measures separately. ${ }^{1}$ Therefore, the aggregate effect is likely to be manifest in parking location and mode split changes. The bulk of the analyses in this paper is concerned with estimating the effect of parking measures on these two quantities.

\section{EMPIRICAL SOURCES}

There are two types of information source available: cross-section and time series. The former compares the travel demand response of different individuals or groups of individual at one point in time in order to make inferences about behaviour over time, while the latter uses direct observations of such behaviour.

One cross-sectional empirical model, which seeks to be comprehensive in its view of travel demand structures, is the Urban Transport Planning model (UTPM), which was widely used during the 1960 s and 1970 s. This model considers trip-making in terms of a four-fold structure-trip generation, distribution, modal split, and assignment. However, the analysis of parking effects has been somewhat restricted because the aggregated nature of the model prevents the full range of parking policy measures being given expression, and because the use of the notion of generalised costs does not permit empirical estimates of the effect of parking attributes, in isolation.

The result has been that parking demand has tended to be considered more as an output of the UTPM; rather than as a vital part of it, interacting with the other demand elements. Thus, the parking requirements consequent to the predicted traffic flows are normally established, and parking supply is viewed as a means of constraining traffic flows to available road capacity. However, the behavioural response to an excess of parking demand, in terms of the effect on mode choice is not treated, while the effect on parking location, if discussed at all, is treated by the development of a parking location sub-model, which ignores feed-back effects on other parts of the model structure. (See Levison and Pratt, ${ }^{2}$ Bates, ${ }^{3}$ Austin, ${ }^{4}$ Ellis et $a l .{ }^{5}$ and Gur and Beimborn, ${ }^{6}$ for example). However, in general, the UTPM studies are not a fruitful source of information on the general effects of parking measures.

A second source of information on parking measures is the range of disaggregate models of personal travel behaviour, which have undergone rapid development in the last 20 years. In contrast to the aggregate approach, these models have several 
advantages. Firstly by modelling individual or household behaviour, they make fuller use of the information contained in travel data sets. Secondly, because the observations are not averaged over individuals from different socio-economic types or areas, the models may be transferable between areas. Thirdly, smaller data sets with reduced data collection costs may be sufficient. As parking supply is often extremely variable within areas and parking opportunities may be very much related to personal circumstances (access to employer-provided or subsidised parking), disaggregate models would seem to be especially relevant to the analysis of the impacts of parking measures. For the most part, these models deal with modal choice, but several studies of parking location are also available.

There have been few attempts to study the effects of a general urban parking policy. A major problem apart from data availability, lies in the fact that, in practice, parking measures go hand-in-hand with other urban transport policy initiatives, and occur simultaneously with socio-economic changes so that it is difficult both to separate parking from, say, public transport improvement effects and to isolate the effect of transport policy changes in general from the impact of underlying changes in the social and economic structure. ${ }^{7}$ The result has been that studies of parking demand over time have tended to consider isolated parking measures and their effects over the short term, when socio-economic changes are few. Because, it is difficult to characterise non-price measures such as parking bans, these studies have tended to emphasise analyses of price measures. The time series studies fall into two groups: the first is concerned with parking price changes at commercial garages while the second relates to the imposition of charges at work sites. In each case the price effect is measured by before and after counts of vehicles or commuters. This raises the important question of whether a pure demand function is identifiable by this procedure: if supply is constrained either before or after the price change, then the resulting demand change may be over or understated.

\section{THE EVIDENCE OF MODAL CHOICE STUDIES}

As mentioned above, one of the primary objectives of car parking policy is to induce changes of mode. Car sharing, public transport, cycle, and walk modes are all seen as advantageous in this respect. Since the early 1960 s, a large number of studies have been undertaken with a view to determining the factors which influence mode changes, especially between car and public transport modes. While a number of studies have examined modal choice at a zonal, route, or similarly aggregated level (for a recent example, see Lioukas ${ }^{8}$ ), the bulk of them have been disaggregate in nature, and it is these studies which are reviewed here.

\section{Variable Specification and Modal Choice}

It is obvious that if modal choice studies are to provide useful information on the effectiveness of car parking policy measures, then they must contain relevant parking variables. The variables relevant to car parking are, firstly, the money cost of parking, and secondly, the time costs associated with searching for a parking place and travelling between parking and work locations. The usefulness of modal choice studies depends on the manner in which these variables are incorporated in the model. In relation to parking costs, it can be seen from Table I that five of the 19 studies cited specify parking costs as a separate variable, 13 include it in the total money costs of the trip, while one study omits it altogether. Elasticities of mode 
choice with respect to total money costs are useful for parking policy assessments, only if parking costs and other motoring costs are always in fixed proportions, or the responses to changes in these two components of money cost are identical. The fixed proportionality of parking and other motoring costs is obviously an unrealistic assumption to make. The hypothesis of equal responses is also unlikely to hold true as parking costs are fixed or time related payments, while other motoring costs (principally, fuel costs) are distance related. In addition, parking charges are often incurred on a trip by trip basis in the sense that a separate parking money transaction must be undertaken with each trip; fuel purchase on the other hand is made periodically and the fuel consumption characteristic of commuting trips, as opposed to trips for other purposes, may not be known to the motorist. Gillen ${ }^{9}$ has tested the hypothesis of equal co-efficients relating to parking and other money costs on commuting trip data relating to 515 individuals working in Toronto C.B.D. He found that the null hypothesis of equal co-efficients was rejected. When couched in terms of elasticities, the parking charge was found to have five times the effect of relative fare costs (mileage related car costs relative to the public transport fare). This result implies that the equality of parking and other money costs cannot be assumed and should be put to empirical test. A large number of mode choice studies may be, therefore, of little value for the evaluation of parking policy.

For the home to work journey, total car travel time may be broken up into three components-access time from the home to the car, in-vehicle travel time, and egress time from the parking to work locations. The first and last of these components are often called "excess time." Again from the point of view of estimating the effects of different parking policies, it would seem important to treat in-vehicle and excess time differently. As excess time is made up of walking and (in the case of public transport) waiting time, it is likely to be valued differently than time spent in the vehicle. Of the 19 studies examined, ten assess excess time separately, while one includes it in a composite variable, representing time and money costs. ${ }^{9}$ The failure to identify parking costs and excess time as separate variables, represents a source of potential mis-specification in mode choice modelling. It is noteworthy that of the 19 studies examined only two (Talvitie ${ }^{10}$ and Galbraith and Hensher ${ }^{11}$ ) incorporate both variables. Moreover, in-vehicle time comprises two components: one is travel to the environs of the ultimate destination, the other is parking search time, which may involve looking for parking of the appropriate type (cost, duration etc). It is reasonable to suppose that the disutility associated with search differs from that of other in-vehicle time, and merits separate specification in the models.

\section{Empirical Results}

With these points in mind, it is possible to discuss the results from the 12 studies, which specify parking costs or excess times as separate variables. McFadden ${ }^{12}$ examined the car-bus choice for 160 commuters in San Francisco. While he reports detailed results relating to total travel time and total cost variables, he also alludes to additional analyses which assessed parking costs separately. These suggest, but not with sufficient statistical precision, that parking costs are weighted more heavily than mileage related or car maintenance costs.

The study by Brown ${ }^{13}$ of car-bus and car-rail choice commuters in Vancouver departs from the usual procedure adopted in mode choice studies in that stated rather than revealed consumer preferences are used. That is, the commuter is asked to state how his behaviour would change in the face of hypothetical changes in policy variables. One of the policy changes considered by Brown is a virtual doubling of the 


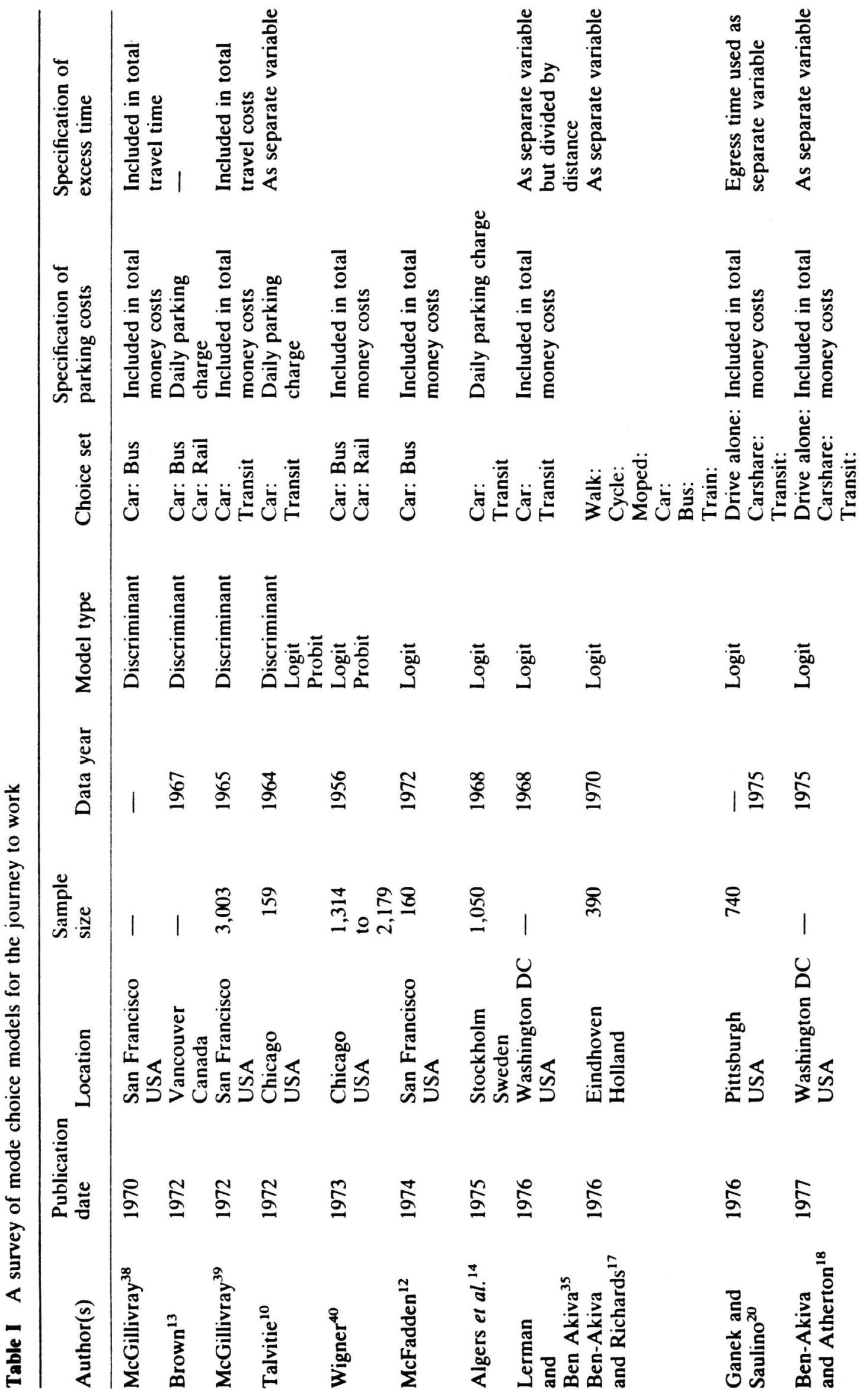




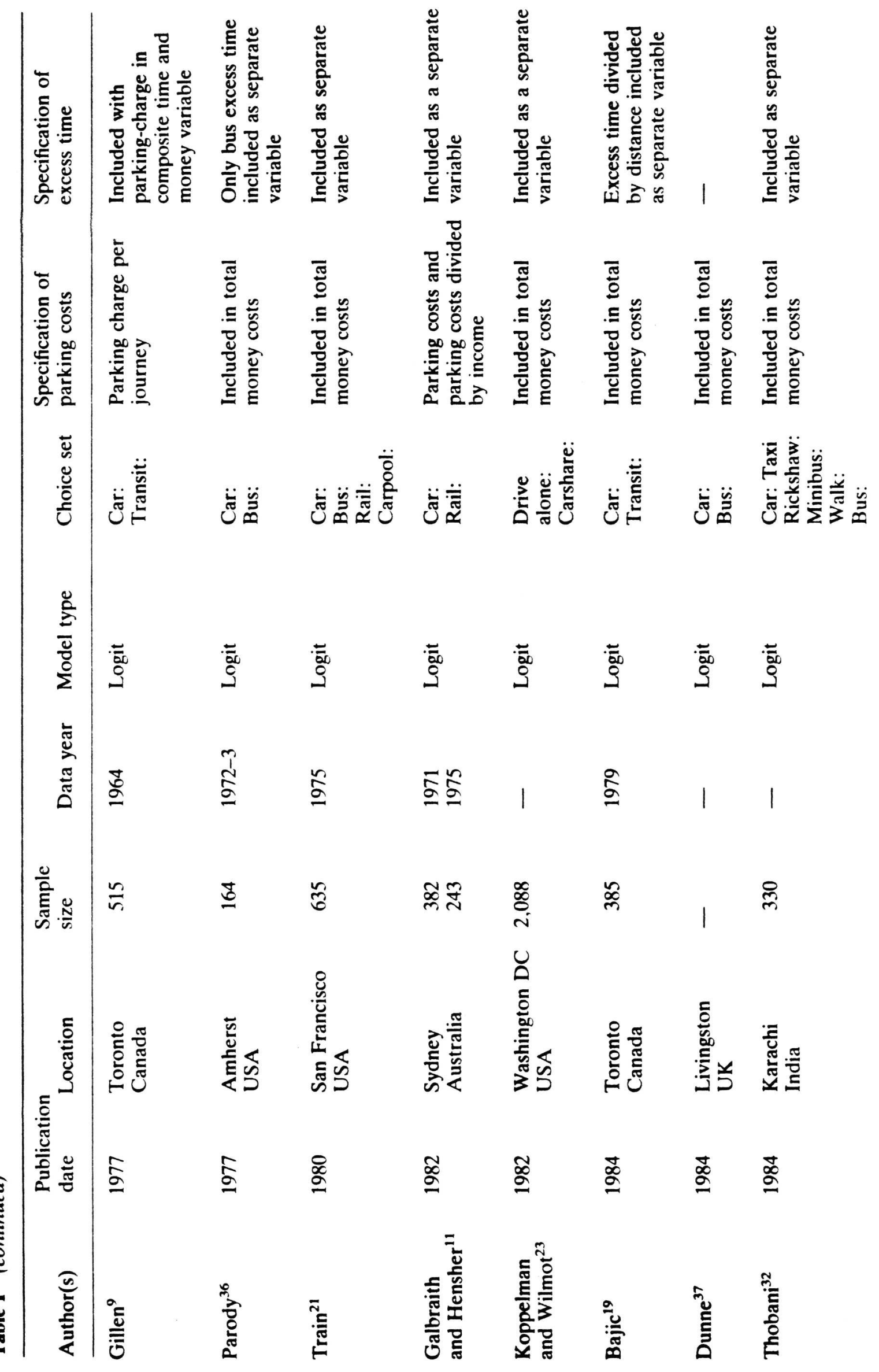


daily parking charge. It is possible from the data presented in the study to estimate the log-arc price elasticity of demand, resulting from this change, at -0.32 that is a $3 \%$ shift to public transport for every $10 \%$ increase in parking charges. Algers et al. ${ }^{14}$ considered the car-transit choice situation for 1050 commuters in Stockholm, again using logit analysis. While car parking costs are specified separately as an explanatory variable, the analysis of car excess time is restricted (somewhat strangely) to access time to the vehicle. It is not possible to estimate even the representative individual elasticity with respect to parking costs from the results presented, as the mean values of the variables, are not given. $\dagger$ It is interesting to note, however, that the size of the coefficient for daily parking charges is somewhat greater than that for the difference variable representing in-vehicle costs. Gillen ${ }^{9}$ also presents an analysis of the effect of parking charges on car-transit choice. Using the method proposed by Westin ${ }^{15}$ to overcome aggregation problems, a weighted parking price elasticity of the probability of car use is estimated at -0.31 . It should be noted that this elasticity is with respect to a ratio variable-parking costs divided by public transport fares. The impact of car excess time is not assessed separately, but included in an alternative specification of a composite variable comprising parking fees plus excess time costs. Thus, not only is it impossible to estimate the elasticity with respect to excess time separately, but it is also unclear as to the effect this has on the estimated parking price elasticity.

Talvitie ${ }^{16}$ does not present the results of his analysis of car-public transport choices in elasticity form. However, he finds that in-vehicle travel time is not significant, but excess time is. The co-efficient with respect to out-of-vehicle costs is less than half that of in-vehicle costs. Ben Akiva and Richards ${ }^{17}$ do not include parking charges even as part of a composite money variable. Because of the absence of information relating to the means of the explanatory variables, it is not possible to calculate elasticities from the logit functions which are calculated; however, the co-efficient values associated with excess time are substantially greater than those for in-vehicle time; in particular, walking time has twice the disutility of in-vehicle time. Ben Akiva and Atherton ${ }^{18}$ do include parking costs, but as part of a composite variable. Excess time is also assessed but as a ratio of distance travelled. It is, therefore, not possible to compare the relative values of in-vehicle and excess time. Bajic ${ }^{19}$ examined the modal choices of 385 Toronto car or transit users using a binary logit formulation. Whereas parking costs were included in total money costs, excess time was evaluated separately. For a 10 minute time change, it was found that the excess time elasticity fell in the range -0.30 to -0.35 , depending on the income level of the commuter. It was also found to exceed that of in-vehicle time by a substantial margin: for the highest income groups a ratio of 6:1 was established. Galbraith and Hensher ${ }^{11}$ calibrated two models relating to the Sydney region (of Australia) in order to examine the geographical transferability of modal choice models. No elasticities are presented and it is not possible to estimate even the representative individual values. However, excess time was again relatively more important than in-vehicle time, although parking costs were not significant. Ganek and Saulino ${ }^{20}$ provide an analysis of 740 commuters with a car, car pooling or public transport choice. Parking charges are not assessed separately, but excess time has, again, a larger co-efficient value than in-vehicle time. Train ${ }^{21}$ and Thobani ${ }^{22}$ both present structured models of car ownership and mode choice. The former finds that the disutility associated with walking is almost double in-vehicle time and four times that of transit in-vehicle

+ Given the non-linear nature of the logit function, the aggregation problem implies that the representative individual approach tends to overestimate the effect of independent variable changes. ${ }^{16}$ 
time. For the latter, the general result holds but the weighting of car and bus invehicle time is reversed. In both studies journey costs are significant.

From the foregoing it is clear that modal choice studies are a limited source of information on the effects of parking measures. While most recent studies distinguish between in-vehicle and out-of-vehicle journey times, none have considered the valuation of the search costs associated with parking. More importantly, the failure to specify parking costs as a variable separate to other journey costs is a major drawback.

Few elasticity measurements are available and these represent different variable specifications. However, a number of common features emerge. Firstly, in general, travel time is found to be an important explanatory of modal choice. When the separate components of travel time are analysed, excess time co-efficients are found to have lower standard errors and higher co-efficient and elasticity values (where estimated) than in-vehicle time. With regard to travel costs, the position is less clear. However, many studies find that total costs are either not statistically significant or are subject to large standard errors (Koppelman and Wilmot ${ }^{23}$ and Ben-Akiva and Richards ${ }^{17}$, for example). Where travel costs are found to be significant, the relevant variable is usually specified to include parking charges. The evidence presented by Gillen ${ }^{9}$ and Algers et al. ${ }^{14}$ indicates that when in-vehicle costs and parking charges are separately assessed, the latter is found to be a considerably more important explanatory of modal choice; however, this result is not supported by Galbraith and Hensher. ${ }^{11}$

In general, the results indicate that out-of-vehicle costs, whether of time or money, are substantially more important in determining modal choice. This supports the view that parking policy measures are likely to be relatively more important than many other traffic management measures in influencing mode choice. Distortions in parking pricing policy are therefore more serious in their implications for modal choice, than distortions in public transport fares or car fuel prices.

As may be seen, for a variety of reasons the number of modal choice studies which are of use for the study of parking policy are few. In order to make modal choice studies more relevant to car parking policy evaluation, a number of conditions must apply:

-the system variables should be more carefully specified; in particular, time and money cost variables should be broken down into their component partswalking, waiting and in-vehicle time

- the implications of the alternative specifications of the system variables-in terms of absolute, difference or ratios-should be examined and their relative efficiency assessed

-the results should be couched in the form of elasticities, calculated using an explicit and accurate aggregation procedure.

\section{THE EVIDENCE OF PARKING LOCATION STUDIES}

As explained above from the point of view of congestion alleviation, the impact of parking policies on mode choice is of great interest. However, changes in parking location may also be desirable, if they help match demand and supply, thereby reducing search times, if they result in diversions to less congested routes or if they indirectly cause changes in the modal split. This section reviews studies which model 
the location of parking demand. Two types of parking location study are relevant. The first type is disaggregate in nature and models parking location decisions at the level of the individual. The second measures the demand for parking at particular sites.

\section{Disaggregate Parking Location Studies}

The use of disaggregate data to model mode choice, has prompted similar analyses of parking location. One of the first of these is due to $\operatorname{Ergun}^{25}$ who related the proximity of parking location (to ultimate destination) to parking charges and a number of socio economic variables. The model, which is estimated on data relating to Chicago, examines the individual's choice of whether to park within one, two, three etc. blocks of his destination. The effect of parking cost differences on the choice of block is incorporated through the use of a variable representing the rate of change in parking costs by block. Both parking cost variables were found to influence parking location; a $50 \%$ increase in parking costs would give rise to a decrease in the percentage parking in the first block from $60-45 \%$-implying an arc price elasticity of -0.43 . The percentage in the second block would be unchanged, while that in other blocks would increase. A study with a similar methodology was undertaken by Gillen ${ }^{26}$ using data relating to Toronto. He calculates a point elasticity of -0.33 with respect to daily parking charges at the first block; moreover, the elasticity rises for blocks of greater distance, indicating that peripheral parkers are more price sensitive. Gillen also estimates elasticities with respect of time costs, which is the same as that for price for the first block, but declines sharply at successive blocks. Both these studies indicate a substantial tendency for relocation in the face of parking policy measures.

In the European context the differentiation of choices in terms of blocks is not valid. The approach adopted by Van Der Goot $^{27}$ with respect to an analysis of parking choice in Haarlem (Netherlands), is to identify certain groups of parking locations and to model the decision to choose between such groups. The latter were defined in such a way that parking charges and restrictions were uniform within each group. Initially, 22 alternative groups were identified, although these were subsequently reduced to six. The study considers a wide range of factors influencing parking choice-walking time, parking charges, duration restrictions and occupation rates. The use of the latter variable is in contrast to the other studies which assume that market prices adjust to maintain an occupancy rate close to unity. For the journey to work, the study finds that walking times and duration restrictions are statistically significant, although parking charges are not. The study results also indicate consumer preferences for off-street carparks and parking garages.

All of these studies support the view that parking supply restrictions, which increase walking times, have a substantial effect on parking location behaviour. There is considerable, although not universal support for a similar role for car parking charges. If relocation is substantial, will significant mode changes take place? While the evidence of the modal choice studies, which were reviewed above, is positive, there is the possibility of a misspecification in such studies arising from the failure to treat parking location and mode choice simultaneously. Westin and Gillen ${ }^{28}$ have examined this possibility by modelling parking costs as an endogenous variable in mode choice. Their conclusion is that, having allowed for simultaneity, a price elasticity of the probability of car use (for the journey-to-work) of -0.3 with respect to parking costs is appropriate. While confirmation of this result awaits further studies, it does support the view that parking policy measures can bring about moderate changes in both mode choice and parking location. 


\section{Site Specific Studies}

Site specific studies, which are amenable to a convenient empirical interpretation, are concerned primarily with the effect with the measurement of the parking response for a given set of individuals over time. They are especially of value because they consider the range of response to parking prices, thereby allowing the decomposition of the response into the various mode options and parking location changes. In assessing and comparing those studies, it is convenient, once again, to use the concept of price elasticity. Elasticities are unambiguously defined for infinitesimal price changes only. For the large price changes under consideration here, a number of surrogate measures are available, which give differing results. Of the two established methods it is not possible to use the log-arc elasticity in all cases as the base parking charge is sometimes zero and the logarithm of zero is not defined. As a result the linear approximation to the log-arc elasticity is used throughout. This measure is not without its problems: if the initial price level is zero, the elasticity reduces to the percentage change in demand.

\section{Commercial Parking Charges}

Off-street parking lots and garages are virtually universal. It is surprising, therefore, that there is very little evidence in the literature of the effects of altering parking charges at specific locations. The most widely quoted findings are those of Kulash ${ }^{29}$ who examined the effect which a tax levied on parking fees in San Francisco in 1970 had on demand. He found that the effect varied considerably between car parks, but that the overall price elasticity was -0.25 .

The study conducted by Kunze et al. ${ }^{30}$ considered the impact of a major increase in municipal parking fees which took place in downtown Chicago in 1978. For a period of 10 years prior to this, the level of parking charges had been unchanged, and were thus $50 \%$ less than those of competing privately-owned facilities. As a result, municipal car parks were fully occupied by the end of the morning peak, principally by all-day parkers. The price increases varied by location, ranging from $38 \%-56 \%$ for one hour of parking and from $38 \%-123 \%$ for 8 hours. The new short-term fees were less than and the new long term fees were equal to comparable fees at nearby privately operated facilities. There was an overall $72 \%$ reduction in the number of vehicles parking all day at the municipal facilities, but no evidence that they transferred to competing car parks. It is that author's opinion, although no direct supporting evidence is offered, that the bulk of the diverted all-day parkers transferred to transit or car-pooling modes. From data presented in the report it is possible to calculate a linear arc price elasticity of -1.2 for long term parking. In contrast to this the number of short term parkers increased, reflecting perhaps both reductions in the length of stay by existing parkers and additional short term parking by new users attracted by the greater availability of space. Haworth and Hilton ${ }^{31}$ present data on the effect of charges at parks in London, Croyden and Coventry. The results of these studies provide further evidence of a substantial elasticity for long term parking $(-0.74$, in the case of the London study), which partly gives rise to shorter stays. An inelastic demand for short-term parking is also apparent.

\section{Charging for Worksite Parking}

Perhaps the most notable feature of urban parking supply is the proportion of spaces for which no charge is levied. Pickrell and Shoup ${ }^{32}$ report that $85 \%$ of those who 
Table II The effect of charging for workplace parking on modal choice of employees

\begin{tabular}{llllll}
\hline & \multicolumn{2}{l}{ Canadian study } & & \multicolumn{2}{c}{ Los Angeles study } \\
\cline { 2 - 3 } \cline { 5 - 6 } Mode & Before $\%$ & After $\%$ & & Before $\%$ & After $\%$ \\
\hline Drive alone & 35 & 28 & & 55 & 30 \\
Carpool & 11 & 10 & & 13 & 45 \\
Transit & 42 & 49 & & 29 & 22 \\
Other & 12 & 13 & & 3 & 3 \\
Total & 100 & 100 & & 100 & 100 \\
\hline
\end{tabular}

Source: Based on Pickrell and Shoup ${ }^{32}$ and Surber et al. ${ }^{34}$

commute by car in urban areas in Canada and the USA park free of charge. May ${ }^{33}$ suggests that on-street parking controls apply only to between one-tenth and one-third of the urban parking stock. The bulk of uncharged spaces are provided off-street by employers. The lack of control over these spaces represents a considerable deficiency in urban parking policy.

Two types of analysis have been carried out on worksite parking:

i) before-and-after studies of the behaviour of motorists who have had free parking facilities withdrawn or parking charges increased

ii) comparison of two groups of motorists, one of which has free or low-priced parking.

With regard to category (i), instances in which free parking has been abolished offer the opportunity to examine the effects of large price changes. On April 1, 1975, the Canadian Government discontinued free parking for government employees, and imposed a charge equal to $70 \%$ of the commercial market rate. Table II based on Pickrell and Shoup's analysis, describes the resultant changes in commuting behaviour. The numbers driving alone to work decreased by $21 \%$, while public transport use increased by $16 \%$, and other modes by $7 \%$. Surber et al. ${ }^{34}$ report on the ending of free parking at a company in Los Angeles. This company formerly paid $\$ 57.50$ per month per space to provide parking for its employees. In May 1982, solo drivers where asked to pay half of this $(\$ 28.75)$, if they wanted to continue availing of the parking facilities. Those who opted to park elsewhere were subsidised to the sum of $\$ 28.75$, and car poolers were allowed to park free. In May 1983, the parking subsidy for solo drivers, who did not use their car in the course of work, was ended. Solo drivers then had to pay $\$ 57.50$ to park in the building. Before the change $42 \%$ were solo drivers, after full implementation this fell to $9 \%$. Car and van pooling rose from $17 \%-58 \%$, public transport use fell from $38 \%-28 \%$. Compared to the Canadian experience the size of the reduction in solo driving is substantial; however, the latter study includes all car parkers, even those who required their car for business journeys. In the Los Angeles study $30 \%$ of parkers fell into this category and were excluded from the analysis. Adjusting for this by assuming that all business car users drove alone, a fall in solo driving from $55 \%-30 \%$ is indicated, which is more in line with the Canadian experience, but still more substantial. However, the majority of those who ceased solo driving became car poolers. From the data presented by Surber et al. it is possible to calculate the drop in car traffic and to measure the linear "arc" price elasticity of demand for car traffic at -0.1 . A similar analysis of the Canadian data, making reasonable assumptions about the occupancy of car pool vehicles, yields an identical estimate. 
Table III Price elasticities of demand for worksite parking

\begin{tabular}{ll}
\hline Lacation & Elasticity* \\
\hline Washington urban sites & -0.09 \\
& -0.06 \\
& -0.12 \\
& -0.24 \\
& -0.02 \\
& -0.11 \\
& -0.08 \\
& +0.01 \\
& -0.32 \\
Washington suburban sites & -0.30 \\
& -0.01 \\
& -0.02 \\
& -0.03 \\
& -0.00 \\
& -0.01 \\
\hline
\end{tabular}

- Source: Calculated by the author from Pickrell and Shoup ${ }^{32}$; Surber $e t$ al..$^{34}$ and Miller and Everett. $^{24}$

Note: The Washington worksites are in the order given in Tables 1 and 2 of Miller and Everett. ${ }^{24}$

In November 1979, federal government employees in the USA were asked to pay one-half of the prevailing commercial rates for government controlled parking spaces. Miller and Everett ${ }^{24}$ carried out a before-and-after analyses of 15 worksites in Washington DC using a sample of non-governmental sites as a control. As existing charges were nominal, the increases imposed were substantial. In addition, the stipulation of a minimum increase of $\$ 10$ per month meant that, for suburban sites, the fees charged become close to commercial rates. The charges gave rise to a $1 \%-10 \%$ reduction in cars at centrally located sites and a $2 \%-4 \%$ reduction at suburban sites. From the data presented in the study, linear arc price elasticities of the demand for car use may be established for each worksite (see Table III). It can be seen that the elasticities vary substantially but are relatively low ( -0.32 or 1ess), and especially so for suburban sites. The authors ascribe the variation in response to differences in alternative parking supply, attractiveness of other modes, trip lengths and socioeconomic and worksite characteristics.

The second method of examining the effect of price changes is to compare two groups of motorists, one of which has free parking. Pickrell and Shoup report on one such study of a sample of $\mathbf{2 7 5}$ government employees in Los Angeles. Approximately half the sample were county employees who received free parking, while the

Table IV The modal choices of employees with free and unsubsidised parking

\begin{tabular}{lcc}
\hline Mode & Free parkers \% & Tolled parkers \% \\
\hline Drive alone & 72 & 40 \\
Car pool & 16 & 27 \\
Transit & 12 & 33 \\
Total & 100 & 100 \\
\hline
\end{tabular}

Source: Pickrell and Shoup (1980). 
remainder were federal employees who were subject to a charge of $\$ 0.70$ per day. Table IV presents comparative modal choice data for the two groups.

Pickrell and Shoup quote a price elasticity of -0.29 with regard to work trips by the car. This would seem to refer to the elasticity of demand for drive-alone trips. Of more interest from the congestion viewpoint is the reduction in car traffic arising from the price change: some of the reduction in solo driving may be offset by increased formation of car pools. This has different implications than a straight transfer to public transport. Making some reasonable assumptions about car pool occupancies, it is possible to calculate a linear "arc" parking price elasticity of demand for car traffic of approximately -0.2 .

\section{Interpretation of Elasticity Measurements}

The elasticity measures which are presented above, exhibit great variations. In particular there is a marked tendency for these for long term parking at commercial car parks to exceed those for commuter parking at worksites. A fundamental reason for this is that different responses are being measured. Elasticities derived from car park patronage represent the effect of price changes on the volume of cars at that parking site; where as worksite elasticities may measure the effect at a particular site or on the level of car use by worksite employers, wherever they park. In the former case, motorists who transfer to alternative parking locations represent a fall in demand; in the latter case, they do not. If alternative parking is available, then ceteris paribus the elasticities derived from car park patronage will exceed those based on car use by employees. If a particular car park is operated on a commercial basis and if there is inelastic demand for parking at that site, then the car park operator will raise his prices, thereby increasing his revenue and reducing his costs (to the extent to which they vary with patronage levels). If variable costs are negligible then an operator with perfect knowledge of the market will tend to raise his prices until the elasticity approaches unity. Observation of the demand elasticities for such car parks will thus tend to yield estimates close to unity. Thus one would expect, a priori very different elasticities to be observed from commercial sites and municipal sites, where profitability may not be the sole objective of pricing policy. Apart from these fundamental differences, there are other obvious reasons why the elasticities should vary both between and within the two different types of study. These relate to transport network and user characteristics which vary from site to site; possible substitutes in terms of the supply and price of alternative parking locations, availability of alternative modes such as public transport and car pooling, trip distances and their effect on walking and cycling characteristics, work place constraints such as the need for the vehicle for business use and a range of socioeconomic characteristics, are all potential explanators. In particular, if the car user bases his travel decision on a consideration of travel times and costs associated with alternative modes and parking locations, then any analysis which seeks to establish relationships between car use and only one of these costs, namely parking price, is likely to produce inconsistent results. In addition a parking price increase may not have any effect on car use, for example, if the costs of the next best travel option are still considerably higher, i.e. there may be threshold effects. This may go some of the way to explaining the low elasticity values derived from worksites, where the parking charge was not increased to full commercial rates.

The data from commercial parks are not without further problems. In addition to the problems mentioned above, the apparent tendency for elasticities to rise with parking duration, may be misleading. In situations where both long and short term 
charges are raised simultaneously, a reduction in the duration of long term parkers will occur which will give a downward bias to own short term elasticity measures, unless cross-price elasticity effects are explicitly taken into account. Alternatively measurements of the demand changes should be related not to numbers of parkers but to number of parking space hours.

Another area of concern is whether analysis of car park patronage yields pure demand functions. This is especially so in the case of short term demand, for which the supply of spaces is constrained by long term parking. If the car park is operating at or near capacity, then not all those motorists who wish to park at the initial price may be able to do so. If an across-the-board price increase releases space for short term parking, there may be a tendency for short term patronage to increase. Whether there will be a net increase in short-term patronage depends on whether this tendency outweighs the reduction in demand by existing short term parkers. In any any event, the elasticity estimates will be given a downward bias.

In summary, in order to avoid misleading price elasticity estimates and comparisons, further before and after studies should pay greater attention to

i) the definition of the demand variable

ii) possible substitution effects between elements of parking demand

iii) the consideration of non-monetary costs of parking

iv) the money and time costs for competing travel options, and

v) possible supply effects.

\section{CONCLUSIONS}

This paper has reviewed the empirical research relating to the effect of parking measures. Because of the failure to specify parking variables separately from total journey times and costs, few disaggregate modal choice studies provide evidence of the effect on parking measures on modal choice. The available evidence does suggest, however, that parking variables are more important explanators than other journey time or cost elements. With regard to disaggregate models of parking location choice, although again few studies are available, there is general support for the view that parking prices and supply restrictions have considerable impacts on parking location choice. Other studies of parking at commercial sites and work sites display a wide range of results. One explanation for this is that these studies are often concerned with different elements of travel demand. A second consideration is that the models used are poorly specified.

\section{Acknowledgements}

This paper was researched while the author was at the Swedish Road and Traffic Research Institute (VTI). An extended version of the paper with the same title is available as VTI Rapport 308A (1986). The author is indebted to his colleagues at the Institute-Jan Owen Jansson, Paul Weaver, Peter Cardebring and Borje Thunberg-for helpful comments. The usual disclaimer applies.

\section{References}

1. M. D. Abkowitz. "An analysis of the commuter departure time decision." Transportation 10, 3 (1981).

2. M. S. Levinson and C. O. Pratt. "Estimating downtown parking demands: a land use approach." Transportation Research Record, 957 (1984). 
3. J. W. Bates. "A gravity allocation model for parking demand." Highway Research Record, 396 (1972).

4. T. W. Austin. "Allocation of parking demand in a CBD." Highway Research Record, 444 (1973).

5. R. H. Ellis, P. R. Rassam and J. C. Bennett. "Development and implementation of a parking allocation model." Highway Research Record 395 (1972).

6. Y. J. Gur and E. A. Beimborn. "Analysis of parking in urban centres: equilibrium assignment approach." Transportation Research Record 957 (1984).

7. J. Bailey and A. D. Layzell. "Travel behaviour and traffic restraint: a study of households in Oxford." transport and road research laboratory, Supplementary Report 734, Crowthorne, Berkshire, UK, 1982.

8. S. K. Lioukas. "Travel modes and the value of time in Greece." Journal of Transport Economics and Policy XVI, 2 (1982).

9. D. W. Gillen. "Estimation and specification of the effects of parking costs on urban transport mode choice." Journal of Urban Economics, 4 (1977).

10. A. Talvitie. "Comparison of probabilistic modal-choice models: estimation methods and system inputs." Highway Research Record, 392 (1972).

11. R. A. Galbraith and D. A. Hensher. "Transferability of mode choice models." Journal of Transport Economics and Policy XVI, 1 (1982).

12. D. McFadden. "The measurement of urban travel demand." Journal of Public Economics, 3 (1974).

13. G. R. Brown. "Analysis of user preferences for system characteristics to cause a modal shift." Highway Research Record, 417 (1972).

14. S. Algers, S. Hansen, and G. Tegner. "Role of waiting time, comfort and convenience in modal choice for the work trip." Transportation Research Record, 543 (1975).

15. R. B. Westin. "Predictions from binary choice models." Journal of Economics, 2 (1974).

16. J. P. Dunne. "Disaggregate mode choice models and the aggregation issue-some empirical results." Transportation Research 19A, 4 (1985).

17. M. Ben-Akiva and M. G. Richards. "Disaggregate multimodal model for work trips in the Netherlands." Transport Research Record, 569 (1976).

18. M. Ben-Akiva and T. J. Atherton. "Travel demand predictions: carpooling." Journal of Transport Economics and Policy xi, 3 (1977).

19. V. Bajic. "Choice of travel mode for work trips." Some Findings from Metropolitan Toronto. International Journal of Transport Economics XI, 1 (1984).

20. J. Ganek and R. Saulino. "A disaggregate modal split model for work trips involving three mode choices." Transportation Research Record, 610 (1976).

21. K. Train. "A structural logit model of auto ownership and mode choice." Review of Economic Studies XIVI (1980).

22. M. Thobani. "A nested logit model of travel mode to work and auto ownership." Journal of Urban Economics, 15 (1984).

23. F. S. Koppelman and C. G. Wilmot. "Transferability analysis of disaggregate choice modals." Transportation Research Record, 895 (1982).

24. G. K. Miller and C. T. Everett. "Raising commuter parking prices-an empirical study." Transportation 11, 2 (1982).

25. G. Ergun. Development of a Downtown Parking Model. Highway Research Record, 369 (1971).

26. D. W. Gillen. "Parking policy, parking location decisions, and the distribution of congestion." Transportation 7, 1 (1978).

27. D. Van Der Goot. "A model to describe the choice of parking places." Transportation Research 16A, 2 (1982).

28. R. B. Westin and D. W. Gillen. "Parking location and transit demand-a case study of endogenous attributes in disaggregate mode choice models." Journal of Econometrics, 8 (1978).

29. D. Kulash. "Parking taxes for congestion relief: A survey of related experience." The Urban Institute, Washington DC (1974).

30. B. Kunze, C. Heramb, and T. Martin. "Impacts of municipal parking fee increases in downtown Chicago." Transportation Research Record, 786 (1980).

31. S. L. Haworth and I. C. Hilton. "Parking elasticity-a tool for policy implementation?" Traffic Engineering and Control 23, 718 (1982).

32. D. H. Pickrell and D. C. Shoup. "Employer subsidised parking and work trip mode choice." Transportation Research Report 786, Transportation Research Board, 1980.

33. A. D. May. "Making progress with traffic restraint: The role of research." Transportation Research Record, 906 (1983).

34. M. Surber, D. Shoup and M. Wachs. "Effects of ending employer-paid parking for solo drivers." Transportation Research Record, 957 (1984).

35. S. R. Lerman and M. Ben-Akiva. "Disaggregate model of automobile ownership." Transportation Research Record, 509 (1976). 
36. T. E. Parody. "Analysis of predictive qualities of disaggregate modal-choice models." Transportation Research Record, 637 (1977).

37. J. P. Dunne. "Commuting mode choice in new towns: a case study of Livingston." Scottish Jou. rial of Political Economy 31, 1 (1984).

38. R. G. McGillivray. "Demand and choice models of modal split." Journal of Transport Ecomonics and Policy IV, 2 (1970).

39. R. G. McGillivray. "Binary choice of urban transport mode in the San Francisco Bay Region." Econometrica 40, 5 (1972).

40. M. F. Wigner. "Disaggregated modal-choice models of downtown trips in the Chicago region." Transportation Research Record, 446 (1973). 
